\title{
Matemática e a inclusão do outro
}

DOI: $10.26512 / \mathrm{lc.v} 24 \mathrm{i} 0.21854$

\author{
Deise Aparecida Peralta \\ Universidade Estadual Paulista \\ Harryson Júnio Lessa Gonçalves \\ Universidade Estadual Paulista
}

\section{Resumo}

Este texto se firma na necessidade de discutir a matemática escolar, como prática social, por um viés inclusivo em oposição a um caráter técnico e segregacionista que, porvezes, parecese apresentar nas salas de aula. Perseguindo os pressupostos habermasianos da Teoria da Inclusão do Outro, propomos uma reflexão desse tema, inicialmente, com um item introdutório sobre o caráter excludente do ensino de matemática escolar, apresentando, a seguir, a matemática entendida como prática social; o pensamento habermasiano, finalizando com a possibilidade de pensar o ensino de matemática como Inclusão do Outro.

Palavras chave: Matemática. Habermas. Ensino. Prática Social. Inclusão. 


\section{Resumen}

Estetextoseafirma en lanecesidad de discutirlas matemáticasescolares, como práctica social, por un sesgo inclusivo en oposición a un carácter técnico y segregacionista que, a veces, parece presentarse en las aulas. Persiguiendo los presupuestos de la Teoría de la Inclusión del Otro, proponemos una reflexión de este tema, inicialmente, con un ítem introductorio sobre el carácter excluyente de la enseñanza de matemáticas escolares, presentando a continuación las matemáticas entendidas como práctica social; el pensamiento habermasiano, finalizando con la posibilidad de pensar la enseñanza de matemáticas como Inclusión del Otro.

Palabras clave: Matemáticas. Habermas. Educación. Práctica Social. Inclusión.

\section{Abstract}

This text is based on the need to discuss school mathematics, as a social practice, by an inclusive tendency as opposed to a technical and segregationist character that sometimes seems to present itself in classrooms. Pursuing the Habermasian presuppositions of the Theory of Inclusion of the Other, we propose a reflection of this theme, initially, with an introductory item on the exclusionary character of the teaching of school mathematics, presenting, next, the mathematics understood as social practice; the Habermasian thought, ending with the possibility of thinking the teaching of mathematics as Inclusion of the Other.

Keywords: Mathematics. Habermas. Teaching. Social Practice. Inclusion. 


\section{Résumé}

Ce texte est basé sur la nécessité de discuter des mathématiques scolaires, en tant que pratique sociale, pour un biais inclusif par opposition à un caractère technique et ségrégationniste qui semble parfois se présenter dans les salles de classe. Poursuivant les présupposés Habermasiens de la Théorie de I'Inclusion de l'Autre, nous proposons une réflexion de ce thème, d'abord, avec un article introductif sur le caractère d'exclusion de l'enseignement des mathématiques scolaires, présentant ensuite les mathématiques comprises comme pratique sociale; la pensée Habermasienne, se terminant par la possibilité de penser l'enseignement des mathématiques comme Inclusion de l'Autre.

Mots-clés: Mathématiques. Habermas. Enseignement. Pratique sociale. Inclusion

\section{Introdução}

Segundo Shapiro (2016), diz-se que na entrada da Academia de Platão lia-se "que ninguém ignorante de geometria entre aqui" (p.19). A filosofia platônica que se rendia à máxima de que o treino matemático é o mais adequado para compreender o universo de forma objetiva, refletindo sobre o status da matemática na aquisição do conhecimento racional. Essa forte corrente fundada na razão pura, aparentemente ainda permeia o ideário acerca da matemática como área do conhecimento, orientando aquela dimensão que é objeto de ensino nas escolas.

Nesse sentido, o ensino de matemática, a julgar pelos resultados em avaliações externas realizadas (Secretaria da Educação do Estado de São Paulo, 2017) e a forma como estes sistemas de avaliações em larga escala (SALE) adentram as escolas (Peralta, 2012), aparenta reforçar uma divisão entre grupos que "sabem matemática", e podem adentrar ao pórtico "da Academia"; e os que "não sabem matemática", ficando do lado de fora, por vezes, sendo considerada a expressão "saber matemática", no contexto escolar, com o teor conceitual preconizado pelos SALE e que se orienta pelo amplo ou parcial domínio de competências e habilidades descritas em matrizes de referência (Secretaria da Educação do Estado de São Paulo, 2009).

Essa possível divisão pode corroborar com um processo de exclusão dos que compõem o segundo grupo citado uma vez que a experiência do fracasso escolar (ou suposto fracasso, pensando na possibilidade dos dados de SALE serem passíveis de questionamento) acaba por promover vulnerabilidade psicossocial (Rutter, 1987, como citado em Santos \& Marturano, 1999). Santos e Marturano (1999) já defendiam que o 
fracasso escolar denotado por "notas baixas" está associado ao risco de má adaptação social, sentimento de auto-ineficácia em crianças pequenas e ao envolvimento com drogas, incidentes criminais, conflitos em relacionamentos e evasão escolar em adolescentes.

O desempenho insatisfatório em atividades escolares, associado à desvalorização da educação e à incompreensão dos pais quanto à sua importância, agravam problemas familiares que envolvem suporte a crianças e adolescentes para permanência na escola, tornando-se muitas vezes um fator de risco para o futuro deles (Ferreira \& Marturano, 2002). Não dificilmente, podemos aceitar histórias de famílias que "investem" nos filhos "mais inteligentes", apoiando-os a seguir na escola e encorajando os que "não dão para os estudos" a seguirem alternativas para se sustentarem economicamente. E não mais dificilmente ainda temos o desempenho em matemática como critério para discriminar "os inteligentes" daqueles que "não dão para os estudos".

Como o sistema educacional oferece poucas alternativas para as crianças e jovens que "fracassam" em aprender matemática, a escola tende a ver esse estudante como diferente, deficiente e o fracasso escolar como deficiência em aprender. Muitas vezes, são responsabilizados o estudante ou a família, eximindo o próprio sistema escolar da reavaliação do seu modelo (Sena, 2015).

Ao longo do tempo, esse "modelo" tem assumido características que perpassam pela ênfase em memorização e mecanização (décadas de 40 e 50); em simbolismo (década de 60); em formalismo teórico (década de 70); em resolução de problemas (década de 80); em aplicações contextualizadas (década de 90); e nas últimas duas décadas a ênfase recaiu sobre o desenvolvimento/construção/constituição, dependendo do referencial adotado, de competências e habilidades prescritas em diretrizes curriculares e de avaliação em larga escala. Assim sendo, há uma aparente preocupação com prescrições acerca do que deve ser inserido na sala de aula para o ensino de matemática e não em fomentar aprendizagens nas próprias relações que se estabelecem lá dentro. Enquanto na sala de aula houver espaço para práticas que se impõem de fora para dentro, a matemática pode nunca ser experienciada como uma prática social acessível a todos em seus conceitos e métodos.

Se a matemática, como componente curricular nas escolas, assumisse seu status de prática social, a visão de ensino focado no desempenho final daria lugar ao de aprendizagem como construção mediada socialmente. Uma visão da aprendizagem como um fenômeno situado e construído socialmente, tendo a linguagem (que representa um dos principais vínculos de um grupo social) como fator essencial, representaria uma mudança fundamental na forma de analisar a aprendizagem de conceitos da matemática dentro e fora da escola, mudança essa permeada pela preocupação com aspectos de Incluir o Outro ${ }^{1}$.

1 As expressões Inclusão do Outro, Incluir o Outro são grafadas com inicial maiúscula quando se tratarem de constructo carregado de teoria habermasiana. 
Eis então uma premissa para que a matemática nos currículos escolares seja um componente agente de inclusão: o ponto de partida na análise da aprendizagem ser a partilha da prática social e não o desempenho. A aprendizagem passa a ser entendida como aspecto indissociável de uma prática social, constituinte e ao mesmo tempo responsável pela completude dessa prática. Assim sendo, todos os membros de um grupo social deveriam ter condições para se apropriar de uma prática comum ao seu grupo. Nesse sentido, a matemática escolar2, aquela que se "aprende" e se vivencia nas escolas, precisa se pautar pelo movimento que acontece desde a escola e não para a escola. É necessário uma revolução ou um câmbio de paradigma para que haja uma avaliação suficientemente crítica dos discursos e das práticas institucionais às quais está sujeita.

Nessa perspectiva, a matemática, assim como toda prática social, seria ensinada como construção humana da qual temos o direito de partilhar e, não tão somente como uma ciência formalista, homogeneizadora, distanciada do ser e do social, asséptica ao cotidiano, fundamentada na preexistência da realidade ao sujeito e por consequência, excludente.

Diante do exposto, e defendendo um conceito de matemática como prática social, e o seu ensino fundamentado em pressupostos socialmente inclusivos, parece pertinente refletir sobre o potencial da Teoria da Inclusão do Outro (Habermas, 2002) na desconstrução do caráter segregacionista da matemática escolar.

\section{Matemática como prática social}

Nós, que vivemos em determinado contexto social, fazemos parte de um grupo marcado por uma cultura caracterizada por condutas habituais significadas internamente e que, por vezes, sem valor em outro grupo cultural. Desta forma, podemos falar de práticas sociais para nos referirmos a este tipo de comportamento social aceito por um grupo que partilha de uma mesma cultura ${ }^{3}$.

As práticas sociais se relacionam diretamente com a tradição de transmissão por e entre as gerações. Sendo assim, pensar "matemática como uma prática social é aceitá-la como um conjunto de conhecimentos construído e compartilhado por uma comunidade de pessoas que compartilhavam meios, métodos e finalidades" (Miguel, Garnica, Igliori \& D’ambrosio, 2004, p. 82). Nesse sentido, entendemos a matemática

2 É a matemática enquanto componente dos currículos escolares.

3 Aqui fazemos uma ressalva quanto ao fato de entendermos, e por isso não nos rendermos, ao que Dutchazky e Sklia (2000) denominam de mito dos sujeitos como membros plenos de uma cultura - a ideia da igualdade, em que todos os membros de uma cultura a vivem da mesma forma. Dentro da "nossa cultura" há sujeitos com identidade comunitária em relação á matemática. 
como prática plural com possibilidades de disciplinarização 4 , sem, no entanto, ser essa sua finalidade maior, e seu ensino percebe-se em formas mais abrangentes em relação ao contexto social em que se situa, não sendo meramente reprodutor da construção alheia (a saber dos chamados matemáticos), mas um fenômeno a ser partilhado, de preferência intersubjetivamente entre os membros de um grupo social de uma mesma cultura histórica e politica, por gerações.

Isto posto, fundamentalmente, temos, segundo Santos Fernandes (2016): uma necessidade política da comunidade que faz e aprende matemática em autorregularse e o investimento em esforços para compreensão de quais são e como operam as concepções de conhecimento. Traçando um paralelo ${ }^{5}$ com Santos Fernandes (2016), ousamos dizer que a matemática como prática social está para além do âmbito de normatizações e regulamentações de ações profissionais e de pesquisa, se manifestando em um cenário de problematização dessas normatizações, tidas como provisórias, a se compor com essas ações, a preservar o direito de todos os indivíduos de compartilhá-la. Nesse aspecto, a matemática escolar não pode ser considerada

anterior às relações que se estabelecem em sala de aula, mas junto a elas, no constante processo de todos os pertencentes ao grupo se fazerem presente nessa relação. Se assim não o for, corremos o risco do difícil acesso à matemática como retórica social, continue o sendo na retórica escolar. (SANTOS FERNANDES, 2016, p. 309)

Pensar matemática como prática social parece não se ajustar aos critérios clássicos de demarcações de campos de conhecimento (Viola dos Santos, 2012), equivalendo a pensar além da dissociação entre conhecimento e sujeito aprendente. Não se tratando, portanto, apenas de pensar como os sujeitos que fazem matemática, mas sim como são produzidas as subjetividades intersubjetivas inerentes à construção do conhecimento que caracteriza tal ciência e isso deveria ser considerado ao se pensar o seu ensino. Entendemos aqui que a intersubjetividade é nesse sentido via propulsora desse tipo de prática.

Aprender matemática envolve a pessoa na sua totalidade e pode ser entendido como uma das dimensões da matemática como prática social, implicando não apenas em uma relação com atividades específicas, mas em uma relação com comunidades sociais (Mattos, 1999). Entendemos que implica tornar-se participante de um grupo de pessoas que se comportam de uma determinada forma diante e em relação à matemática. Os conceitos, método, intenções e tradições da matemática e seus possíveis entendimentos não podem existir senão como partes de relações mais gerais com significado para um grupo social.

4 Em Santos Fernandes (2016) encontramos que disciplinarização pode ser tomado pelo processo de constituição de uma disciplina a partir de uma prática social.

5 Usamos a mesma lógica de pensamento que Santos Fernandes (2016) tece em relação à Educação Matemática para falarmos de Matemática Escolar. 
Aprender significa tornar-se uma pessoa diferente com respeito às possibilidades trazidas por esse sistema de relações para atuar com/em/a partir de, principalmente, aquele grupo. Ignorar este aspecto da aprendizagem é não perceber o fato de que aprender envolve torna-se pertencente a um grupo. (Lave \& Wenger, 1991,p. 53)

O conceito de matemática escolar como fenômeno situado em uma prática social requer aceitar que ensinar e aprender são dimensões dessa prática e que compartilhála com todos os outros pertencentes ao grupo social é uma necessidade. E essa necessidade perpassa pelo conceito de alteridade, cuja índole filosófica nos remete à noção de reconhecer-se no outro, mesmo que a princípio existam diferenças físicas, psíquicas e culturais. Então, matemática como prática social pressupõe partilhas e construções intersubjetivas que só se efetivam na legitimação, via alteridade, da Inclusão do Outro.

\section{Habermas e a Inclusão do Outro}

Jürgen Habermas, considerado um dos pensadores mais destacados da segunda geração da Escola de Frankfurt, afirma que toda ciência supõe uma relação com determinado objeto (que em sua obra Conhecimento e Interesse trata como interesse) como parte constitutiva do conhecimento e da razão (Habermas, 2002). Pensar sobre qualquer assunto é feito dentro do contexto de uma sociedade, geralmente, muito competitiva. Portanto, qualquer pensante sempre persegue também objetivos concretos. Assim, conhecimento nunca é neutro e, por consequência, as ciências também não são.

De acordo com o objeto de interesse que as fundamentam, Habermas (2002) categoriza três classes de ciências: empíricas (razão regulada pela objetividade); histórico-hermenêuticas (prática regulada pela intersubjetividade); e emancipativas (emancipação orientada pela reflexão crítica). É desse terceiro tipo, ciências emancipativas, que Habermas se ocupa em teorizar. Nessas ciências, a teoria deixa de ser mera teoria e coincide com a práxis, pois em ambos os casos coincidem o conhecimento (teórico) com o interesse (prático): a crítica à sociedade não consiste em um mero compreender, senão na emancipação das diversas formas injustas de dominação e o simples compreender já é o início da libertação (Habermas, 1987). Habermas se ocupa por excelência das questões acerca da democracia, no sentido da existência de condições para que o contexto social seja inclusivo.

Em Die Einbeziehung des Andersen - Studien zur politischen Tehorie (em português: A Inclusão do Outro - Estudos de teoria política), Habermas (2002) discute inclusão, 
partindo de um olhar para as diferenças nas chamadas sociedades democráticas. É um ensaio referente às questões básicas de sua filosofia moral que explicita a necessidade de pormenorizar princípios sociais democráticos fundados em ideais de Inclusão do Outro.

Tal necessidade se dá por entender que nessas sociedades, por mais que se declarem democráticas, há uma cultura majoritária que, ao exercer o poder político, impregna nas minorias ${ }^{6}$ sua forma de vida, ocasionando violação a uma efetiva igualdade de direitos, no que se refere ao autoatendimento ético e a identidade de cada um. (Araújo, 2016, p. 96)

Tal violação, segundo Habermas (2002), ocorre porque mesmo as pessoas pertencentes a um mesmo grupo social, legalmente reconhecido, ainda serão vulneráveis se tais grupos forem caracterizados dentre as chamadas "minorias". Uma sociedade democrática, ao adentrar no campo das questões ético-políticas, nas formas em que as vidas se apresentam, têm sua configuração afetada, necessitando de autoanálise. Ou seja, os sentidos e valores culturalmente especificados e compartilhados sem tradições intersubjetivas devem ser reanalisados. Não se trata apenas de um discurso "progressista" em aparência frente a um discurso de não inclusão; trata-se, pois, de proposição que discuta as condições, para todos e cada um dos sujeitos, percebendo os efeitos específicos em cada caso e, sobretudo, debater a ética do processo. (Freitas \& Coura, 2014)

Habermas (2002) analisa o papel desempenhado pelos contextos sociais, culturais e institucionais aos quais se vinculam os discursos práticos ${ }^{7}$, bem como desafios a serem superados na efetivação da Inclusão do Outro. A esta altura, Habermas sofria influência, a saber em Faktizität und Geltung (em português: Facticidade e Validez), da tensão entre os normativistas e a filosofia política e jurídica contemporânea (Habermas, 2005).

Dessa forma, subsidiado pela teoria discursiva do Direito e do Estado, desenvolveu a teoria acerca da Inclusão do Outro, considerando os distintos âmbitos e problemas do mundo atual. Para tanto, aplica em sua teorização os princípios democráticos da política deliberativa: a tomada de consciência do caráter global dos direitos humanos, a globalização dos meios de comunicação, a crescente diversidade cultural das sociedades contemporâneas e seus conflitos com a globalização, o esvaziamento da democracia, a progressiva integração dos mercados, dentre outros (Freitas \& Coura, 2014, s/p).

6 Na referida tradução da obra de Habermas encontramos o termo "minoria". No entanto, entendemos que em sentido quantitativo é possível, atualmente, questionar se as pessoas que formam "as minorias", ou seja, as que mais sofrem as opressões sistêmicas, em termos quantitativos não poderiam ser consideradas maioria oprimida (aqui leia-se opressão no sentido freireano) por uma minoria repressora?

7 Segundo Habermas, as pretensões de validade, ligadas a cada ato de fala, podem ser problematizadas, e quando a problemática se encontra nas pretensões de verdade, correção ou inteligibilidade, ocorre à passagem da ação comunicativa para o que Habermas chama de discurso. O discurso quer dizer que o falante tem que fazer uso de argumentos para justificar que suas asserções são verdadeiras (discurso teórico), que uma determinada ação ou norma de ação seja correta (discurso prático), ou ainda explicar algo incompreendido pelo meu ouvinte (discurso explicativo). 
Todas essas perspectivas o levam a considerar que o direito de manter a própria vida cultural e a obrigação de aceitar o marco político de convivência definido pelos princípios constitucionais e os direitos humanos devem coexistir sem prejuízos, fazendo com que surja uma tentativa de impedir que a identidade coletiva se torne um mecanismo de exclusão (Gilli Martins, 2005). Exclusão aqui pode ser entendida como intenção consciente de homogeneidade social, resultando em marginalização de grupos sociais inteiros.

A política própria de uma democracia deve ser direcionada à Inclusão do Outro, reconhecendo as normas de direito estabelecidas que versam sobre um conteúdo universalista de princípios constituintes onde cada situação se apresenta como especificidade num contexto maior da história geral, considerando uma tradição, uma cultura e uma forma de viver que se apresenta, mas não pode se justificar como predominante nesse espaço. Na regulação de temáticas culturalmente que despertam o interesse amplo na sociedade, a saber as chamadas polêmicas", acaba por prevalecer o entendimento, que diríamos talvez ser autoentendimento, ético-político próprio de cultura "majoritária"8, dominante por motivos econômicos, políticos e históricos. Sendo assim, todas as "minorias" que se diferem dessa cultura "majoritária" entram em conflito cultural, afinal as regras universais são altamente repressivas no que se refere ao mundo da vida de cada um, mesmo dentro de uma comunidade que "garanta formalmente" igualdade de direito de todos. (Durkhein, 2004; Habermas, 2002)

Em um contexto de cultura "majoritária" instituída, a "minoria" discriminada/ segregada/excluida só pode reaver a equidade por meio da secessão na concentração de poderes dos que pertencem a um espaço, seja ele institucional ou não. Segundo Habermas (2002), a discriminação não é abolida totalmente pela secessão prevista por instrumentos legais, mas quando há uma inclusão sensível à origem cultural legítima das diferenças individuais específicas. $O$ autor afirma que a inclusão, para ser efetiva às minorias, deve ser sensível às diferenças, trazendo mudanças fundamentais para o indivíduo sem tocar nos princípios universais necessários ao coletivo, prevendo arranjos diversos que protejam as "minorias", ou seja, que tratem da proteção aos que mais sofrem com as relações de opressão.

Em Erläuterungen zur Diskursethik (em português: Comentários à Ética do Discurso), Habermas (1991) já dava sinais da relevância da Inclusão do Outro - mesmo que inicialmente e em estágio de pré-vinculação com seu sistema filosófico, defendendo que em uma comunidade comunicativa, em sua forma ideal, há o abandono de todos os pré-conceitos sociais e uma pessoa pode constituir e publicizar sua identidade. As interações que formam o eu também ameaçam sua existências uma vez que dependem das contingências a que ele se expõe, portanto o eu só existe na relação com o outro.

Em Faktizität und Geltung (em português: Direito e Democracia), Habermas (1997) afirma que uma nação de cidadãos só pode se desenvolver por processos sociais onde

8 Entendendo por "majoritária" aquela que domina pela força da opressão. 
as formas de vida formam uma identidade que compõe o contingente do povo em uma unidade política que não privilegia a exclusão das "minorias". A coexistência, com igualdade de direitos para toda a mais ampla diversidade de pessoas, não significa a fragmentação da sociedade. Dessa forma, Habermas (1997) entende que a cultura política comum deve ser coesa para que a nação, em determinados campos políticos, não se aniquile. No entanto, o autor ressalta que, em nome disso, a cultura "majoritária" não pode se posicionar como uma política geral para que não se padronize/uniformize/ homogeneíze ou pasteurize os discursos de autoentendimento, impedindo a Inclusão do Outro. Trata-se de garantir e proteger o diverso na promoção da unidade.

\section{A matemática escolar, como dimensão de prática social, e a teoria habermasiana}

Aceitando a matemática escolar como uma das dimensões da matemática e essa última como prática social, a primeira então pode ser entendida como dimensão de uma prática social. Dimensão essa com possibilidades de ser agente por excelência de socialização de conceitos, finalidades, meios e métodos da matemática para todo um grupo social, caso não negligencie uma série de fatores políticos e culturais. Dentre tais fatores a teoria habermasiana nos faz perceber de maneira especial: a Inclusão do Outro.

Como anteriormente descrito, Habermas (2002) articula o problema da Inclusão do Outro de maneira não simplista em termos de uma inclusão sentimentalista travestida de paternalismo - paternalismo, por vezes, costuma ser também uma forma de exclusão social; mas, para muito além disso, demonstrando substratos genealógico-cognitivos da moral, preceitos democráticos e princípios normativos legais, apresentando ainda a via da alteridade fundamentada na razão comunicativa. Ele expõe argumentos que nos convidam a pensar sobre como a normatização pressupõe, ao menos em certa medida, um término ou uma pausa no diálogo. Nesse sentido, e a título de exemplo, podemos citar que a educação matemática escolar pode objetivar que formas mais inclusivas para o ensino de matemática sejam constantemente pauta de discussões, mas enquanto objetiva, não pode se esquecer que as políticas curriculares estão em movimento e acontecendo enquanto se discute sobre elas. $O$ ensino de matemática, na perspectiva da Inclusão do Outro, envolve movimento constante de discussão e vigilância às dimensões legais e curriculares. Assim sendo, e ainda segundo Habermas (2002), inclusão não tem relação direta com assistencialismo acrítico de qualquer natureza e sim com uma cultura de responsabilidade compartilhada não confinada ao espaço escolar com finalidade única de assegurar aprendizagem de "conteúdos", mas aproximando-se a ideia das pessoas, todas as envolvidas e sem exceções de qualquer e por qualquer natureza, como configuradores do currículo. E, para tanto, garantias 
legais, políticas e pedagógicas, firmadas em vias alternativas à racionalidade técnica, são necessárias.

As diretrizes curriculares para o ensino e avaliação de matemática, como se pode observar em seus dispositivos e regulações, não consideram os distintos âmbitos e problemas do mundo atual que não se resumem unicamente ao desempenho de quem aprende, mas dos quais o desempenho, em parte se pode afirmar, se torna uma trágica consequência (Peralta, 2012). Assim, o que deveria ser um "norteador" (matrizes de referência, descritores de aprendizagens), para adequar condições de ensino à necessidade de quem aprende, se torna prescritor de ações em busca de resultados padronizados, dando a falsa impressão de que os problemas na gestão dos processos são inexistentes, quando na realidade eles se atenuam em nossa ausência de consciência. Nesse sentido, tal como nos alerta Fernandes (2011), as políticas curriculares que deveriam defender princípios que apelam à equidade nas vias de oportunidade, à participação e à diferenciação pedagógica acabam por coexistir com "princípios fundados na eficácia e na competitividade" (p. 135).

Assim sendo, pensar o ensino de matemática na escola, na perspectiva da Inclusão do Outro, expressa a necessidade de ultrapassar uma visão de currículo como um conjunto de normas a cumprir, supostamente, de maneira homogênea em todas as salas de aula, despojando-o do sentido de uniformidade e introduzindo um conceito de matemática para além da visão utilitarista e funcionalista de ferramenta para (re) solver "problemas". Diz-se isso pois a visão de matemática como ferramenta, seja para resolver problemas do cotidiano ou do próprio universo dos matemáticos ou de outras ciências, coloca o aprendente em posição de quem domina ou não a faculdade dela fazer uso. Se a dominar, resolve o "problema"; caso contrário, não resolve o "problema" e, nesse último caso, qual o papel da matemática na vida de quem está a aprender (ou não) matemática? Se permitir pensar o ensino de matemática como Inclusão requer uma visão ampla de matemática (como prática social e dentro do paradigma de ciências emancipativas, por exemplo) e abandonar uma visão restrita e restritiva de matemática (por exemplo como ferrramenta e de acordo com paradigmas objetivistas- empiristas).

Destacamos que a centralidade da discussão não se refere diretamente à problemática de utilização do termo "ferramenta", mas sim ao seu uso imbuído de uma carga ideológica que a concebe meramente numa perspectiva utilitarista e funcionalista voltada para resolução de "problemas" - que infelizmente percebemos comum entre educadores matemáticos.

Parar de perseguir o ideal de aprendizagem da matemática como domínio/ desenvolvimento/construção de competência e habilidades, potencializando o grande fetiche da ferramenta para (re)solução de problemas, e vislumbrar que ser aprendente de/em matemática é tornar-se parte de um grupo que partilha cultura. Nesse sentido, o ensino de matemática poderia deixar o status de partícipe no processo de educação como adaptação social, que acaba por corroborar com uma sociedade que preza a 
uniformidade, a seletividade e a competitividade (onde quem domina a ferramenta matemática acaba por ter mais oportunidades no sistema social e econômico) e assumir a postura de fundante de um ideal de educação como transformação social, defendendo princípios de democracia, equidade e Inclusão do Outro.

Para concretização do referido ideal, assumimos ser urgente repensar a perspectiva centralizadora do currículo, tão somente impregnada no ideário uniforme e prescritivo dos que pensam bases curriculares comuns para nações inteiras, e considerar, seriamente uma perspectiva contextualizadora e comunicativa ${ }^{9}$ de currículo. $\mathrm{Ou}$ seja, urge uma concepção de ensino de matemática estruturada em princípios como diferenciação e diversidade pedagógica, participação coletiva, partilha, diálogo, legitimação de todos perante a cultura a que pertence. E mais urgente ainda é pensar a matemática como prática, e não somente como produto de práticas, a ser configurada como ferramenta, adotando uma explicação fundamental das relações sociais e da natureza humana a ela associada como parte do conhecimento que a caracteriza e, principalmente, que lhe dá sustentação epistêmica. Aceitar matemática como ferramenta é validar que, como ciência, ela se perpetua dentro de paradigmas puramente racionalistas e objetivistas, minimizando possibilidades de emancipação e intersubjetividade em seus processos.

Certamente a matemática tem vital importância no esforço cientifico centrado no entendimento do mundo material. Há também que se admitir o subsídio que essa ciência oferece às demais desde a constituição da Academia de Platão aos programas educacionais em todas as ciências naturais, exatas e/ou engenharias. No entanto, a razão do seu ensino atualmente é diferente da daquela Academia, pois com o declínio do racionalismo, a matemática passa de paradigma para as ciências empíricas à ferramenta para as ciências que dela se "utilizam" (Shapiro, 2016). E esta função de serviço tem por vezes orientado também as perspectivas metodológicas de seu ensino, dando espaço a processos formativos acríticos em relação a uma concepção filosófica substancial de matemática. Se a matemática é ou não ela própria uma atividade de aquisição de conhecimento, uma prática social, um direito de todos que partilham uma cultura são questões que orientam as práticas pedagógicas em sua dimensão escolar. E não reconhecer ou problematizar essas questões, acrescidas de outras de igual teor filosófico e social, é compactuar com um paradigma que trata a matemática como ciência de "objetos eternos e imutáveis, não sujeitos a construções e movimentos" e, menos ainda, a influências dos grupos sociais que a vivenciam, experienciam e modelam (Shapiro, 2016, p. 25). Neste ponto, defendemos a necessidade de pensar que a concepção que se tem de matemática precede a prática que envolve processos formativos na/para/da matemática escolar em algum sentido metafísico.

Dessa forma, entendemos a necessidade de esmiuçarmos, indiciariamente, as

9 Comunicativa no sentido habermasiano, ou seja, em oposição à racionalidade técnica como orientadora do Desenvolvimento Curricular. 
concepções epistemológicas da matemática como ciência, sobretudo numa tentativa de repensar criticamente a sustentação dos paradigmas objetivistas como um laço homogêneo de uma normatividade do que se tem concebido como matemática escolar. De todo modo, a inquirição de Habermas (1988) pode ser profícua ao se engajar em um traço de análise crítica com possibilidades preponderantes de ir além das evidências empírico-analíticas-dedutivas que ainda emaranham o campo teórico da matemática e que impactam em todas as dimensões do seu ensinar. Ao defender a compreensão do objeto com o propósito de entender não somente um modelo estético, mas o estado transcendente interno, Habermas (1988) nos oferece elementos para questionarmos a validação dessa objetividade sob a qual fomos condicionados a nos relacionarmos com a matemática. Assim sendo, consideramos que processos interpretativos e emancipatórios possam ser validados com bases comunicativas e conjuntas para a matemática a partir de uma consciência coletiva concebida e materializada em termos de prática social.

Pensar matemática como prática social requer pensar a imbricação entre o cultural, o político e o econômico, instituindo-se uma esfera política com caráter diretivo e orientada para a realização tanto de processos amplos de inclusão sociocultural quanto de democratização do poder - tal é o sentido da relação entre o saber matemática e o atuar no mundo com/por ela, e as massas que a ela têm acesso como aprendentes. Habermas (2001) nos alerta para isso ao se referir que se consolidam como sociedades democráticas contemporâneas aquelas marcadas por esferas públicas altamente politizadas e críticas dos poderes vigentes em todos os âmbitos e conscientes de que só há democracia se todos os seus membros forem incluídos (Habermas, 2001; Honneth \& Hartmann, 2009). Para o referido autor, só há democracia se houver comunidade pautada em inclusão.

Comunidades existem essencialmente na figura de relações de reconhecimento recíproco entre membros. É por esta estrutura intersubjetiva da comunitarização (Vergemeinschaftung) de pessoas individuais que Hegel se deixa guiar na explicação lógica do conceito de "universal concreto" ou de "totalidade"'. (Habermas, 2004, p. 200)

A Inclusão do Outro habermasiana nos permite relacionar a concepção de "autoconsciência como unidade de universalidade e singularidade à constituição do mundo social pelos processos de socialização e individualização", alertando sempre, influenciado por Hegel, de que o sujeito cognoscente está, enquanto espírito, desde sempre junto de seu outro, buscando uma pertença normativa (Habermas, 2004, p. 188). Neste sentido, o "eu e o outro, ego e alter, entram em relações uns com os outros e, ao mesmo tempo, formam comunidades na consciência de sua absoluta diversidade" (Habermas, 2004, p. 199).

A "pertença normativa" não é contraposta por Habermas (2011), porém por ele é questionada: "Qual é o sentido moral da inclusão?", na tentativa de enfatizar a 
necessidade do respeito ao outro como sujeito de igual direito em sua dignidade humana, tensionando a relação entre direitos humanos universais e direitos civis particulares. Isso posto, e agora trazendo essa discussão habermasiana para a nossa discussão sobre matemática e a Inclusão do Outro, ousamos lançar algumas provocações: Como pensar, da facticidade à normatividade, o conceito de dignidade da pessoa humana e as condições que lhes são dispostas para que se torne parte de uma cultura que partilhe algum tipo de matemática? Qual o papel da matemática escolar na construção de um mundo social onde todos sejam reconhecidos como outros de direitos iguais? Como impedir que a identidade coletiva, que prega desempenhos em matemática com base em scores padrões se torne um mecanismo de exclusão daqueles que não se enquadram nos modelos sistêmicos pré-formatados?

O fato é que, numa visão habermasiana, a exclusão na escola se dá por meio da iniciativa de homogeneização daquele ambiente, resultando na marginalização de grupos sociais inteiros. Não é possível que o ensino de matemática possa exercer o papel por excelência de saneador institucional, excluindo, sistematicamente, aqueles que não respondam aos modelos pré-formatados na/da/para a escola. Contra a exclusão sistemática é preciso a defesa de que a matemática escolar, própria da democracia, deve ser orientada à "Inclusão do Outro".

\section{Considerações finais}

A concepção que se tem de matemática acaba por determinar o que será considerado como matemática escolar. Todavia, aceitar princípios gerais daquela não pode ser confundido com, ou levar à imposição de uma identidade a essa, excluindo ou alijando o diferente.

Aqui ressaltamos o que Habermas (2002) alerta acerca da validade da concepção do que é "ideal", no âmbito de uma ordem estatal conjunta, para a evolução da cultura de uma sociedade. O autor afirma que privilégios ao ser, estar e fazer dos dominantes em detrimento das minorias, no interior do Estado, não podem nunca ter justificação. Assim, o consenso do que seja "ideal" em termos de desempenho em matemática, estabelecido por quem quer que seja, não pode significar qualquer prejuízo ou exclusão daqueles que vivem o diverso do padrão "ideal". A imposição de certos modelos, ou ainda "ideal" de aprendizagem, sem a devida consideração de todo o contexto social originário, significa não só privilégio ao que é "ideal", mas a total marginalização daqueles que não se adaptam ao "ideal" e alijamento de direitos dos diferentes (Habermas, 1997).

A busca de mecanismos para aplacar os efeitos nocivos da ampla desigualdade numa sociedade de tamanha pluralidade como a atual, na tentativa de "Inclusão do Outro", 
não é tarefa simples, sem dúvida. Fácil também não é o estabelecimento de consensos acerca de qual(is) matemática(s) devem compor os currículos, bem como quais as práticas pedagógicas mais indicadas para romper com a racionalidade eminentemente técnica (Habermas, 1988) que permeia o ensino de matemática. Por outro lado, há que se considerar o direito do Outro a igual respeito e dignidade, em especial nos processo em que figura como aprendente, inclusive quando se trata de partilhar a matemática praticada pelo grupo do qual tem o direito de pertencer (Miguel et al, 2004).

A barcaça social da exclusão escolar, em que Outro pode se configurar como todo e qualquer um que não corresponda às expectativas sistêmicas, construída com o incentivo dos valores neoliberais da competitividade e da promoção ao sucesso individual, assomados à negligência do Estado na promoção de políticas sociais que promovam uma escola mais democrática, tende a não navegar tão tranquilamente se pensarmos o ensino de matemática entre outras bases que não aquelas que a perpetuam como conteúdo curricular segundo, e seguindo, as intenções e propósitos da cultura majoritária instituída e opressora (Freire, 2011; Habermas, 2009; Skovsmose, 2007).

Nesse sentido, cabe ao movimento da Educação Matemática fomentar tensão interna à própria área acerca do ensino de matemática, se posicionando frente às possibilidades de inclusão ao interpretá-lo de uma forma mais conservadora (com ênfase no respeito à norma constituída e ao conceito utilitarista e funcionalista de "matemática como ferramenta para/de resolução de problemas" em um paradigma objetivista - empirista de ciência) ou emancipadora (propiciando a mobilização para subordinar dimensões sistêmicas à forma consensual de integração social característica de um conceito de matemática como prática social e de um paradigma de ciência emancipativa). Se posicionar é preciso!

\section{Referências}

Araújo, C. S. (2016). Todos os nomes: Jürgen Habermas e o uso do nome social no estado de Goiás. Fragmentos de Cultura, 26, 93-101.

Freire, P. (2011). Pedagogia do oprimido. 50. ed. São Paulo, SP: Paz e Terra.

Durkheim, E. (2004). Da divisão do trabalho social. (E. Brandão, Trad.). São Paulo: Martins Fontes. (Obra oginal publicada em 1893).

Dutchazky, S., \& Skliar, C. (2000). La diversidad bajo sospecha. Reflexiones sobre los discursos de la diversidad y sus implicancias educativas. Cuaderno de Pedagogía, 4 (7), 33-54. 
Fernandes, P. (2011). O currículo do Ensino Básico em Portugal: políticas, perspectivas e desafios. Porto: Porto Editora.

Freitas, C. N., \& Coura, A. C. (2014). A teoria habermasiana de inclusão do outro e a internação compulsória. In: J. A. de Oliveira Jr., R. Tramontina \& A. L. C. Santos (Orgs). Filosofia do direito I. Florianópolis: CONPEDI, 432-446.

Gilli Martins, J. C. (2005). Sobre revoluções científicas na Matemática. Tese de doutorado, UNESP- Instituto de Geociências e Ciências Exatas, Rio Claro, São Paulo, Brasil.

Habermas, J.(1991). Comentários à ética do discurso. Lisboa: Instituto Piaget.

Habermas, J. (1997). Direito e Democracia: entre facticidade e validade. Rio de Janeiro: Tempo Brasileiro.

Habermas, J. (2005). Facticidad y validez: sobre el derecho y el Estado democrático de derecho en términos de teoría del discurso. 4a ed. Madrid: Trotta.

Habermas, J. (1987). Teoría y praxis: estudios de filosofía social. Madrid: Tecnos.

Habermas, J. (2002). A inclusão do outro: estudos de teoria política. São Paulo: Loyola.

Habermas, J. (1989). Consciência moral e agir comunicativo. Rio de Janeiro: Tempo Brasileiro.

Habermas, J. (2009).Técnica e ciência como "ideologia". Lisboa: Edições 70.

Habermas, J. (1988). Teoria de la acción comunicativa: racionalidad de laacción y racionalización social . Madri: Taurus, 1988.

Lave, J; Wenger, E.(1991). Situated learning: legitimate peripheral participation. Cambridge: Cambridge University Press.

Matos, J. F. L. (1999). Aprendizagem e prática social. Educação Matemática em Portugal, Espanha e Itália. Actas da Escola de Verão-1999, 65 - 92.

Miguel, A., Garnica, A. V. M., Igliori, S. B. C., \& D’ambrosio, U. (2004). A educação matemática: breve histórico, ações implementadas e questões sobre sua disciplinarização. Revista Brasileira de Educação, 27, 70-93.

Peralta, D. A. (2012). Formação continuada de professores de matemática em contexto de reforma curricular: contribuições da Teoria da Ação Comunicativa. Tese de doutorado, UNESP- Faculdade de Ciências, Bauru, São Paulo, Brasil. 
Santos Fernandes, F. A. (2016). Educação Matemática Muda. Boletim de Educação Matemática, 30(55), 308 - 324.

Secretaria da Educação do Estado de São Paulo.(2009). Matrizes de referência para a avaliação SARESP: documento básico/Secretaria da Educação; coordenação geral, Maria Inês Fini. - São Paulo: SEE, 2009.

Secretaria da Educação do Estado de São Paulo. (2017). Resultados de Matemática. SARESP em Revista, 1. Recuperado em 20 junho, 2018, de http://saresp.vunesp.com. br/resultadosgeralmat.html

Sena, I. J. (2015). Queixa escolar e adolescência: sentidos construídos em contexto de vulnerabilidade social em Camaçari-Bahia. Dissertação (Mestrado em Psicologia). UFBA - Instituto de Psicologia. Salvador.

Skovsmose, O. (2007). Educação Crítica: Incerteza, Matemática, Responsabilidade. Tradução de Maria Aparecida Viggiani Bicudo. São Paulo, SP: Editora Cortez.

Viola Dos Santos, J. R. (2012). Legitimidades possíveis para a formação matemática de professores de matemática (ou: assim falaram Zaratustras: uma tese para todos e para ninguém). Tese de doutorado, UNESP - Instituto de Geociências e Ciências Exatas, Rio Claro, São Paulo, Brasil. 
Deise Aparecida Peralta: Doutora em Educação para a Ciência, mestra em Psicologia do Desenvolvimento e Aprendizagem e graduada em Matemática pela Universidade Estadual Paulista (UNESP) - professora do Departamento de Matemática da Faculdade de Engenharia do Câmpus de Ilha Soltera (FEIS) da UNESP, vinculada como docente permanente ao Programa de Pós-Graduação em Ensino e Processos Formativos (UNESP), líder do "Grupo de Pesquisa em Currículo: Estudos, Práticas e Avaliação (GEPAC)", deise. peralta@unesp.br.

Harryson Júnio Lessa Gonçalves: Doutor em Educação Matemática pela Pontifícia Universidade Católica de São Paulo (PUCSP), mestre em educação e pedagogo pela Universidade de Brasília (UnB) - professor do Departamento de Biologia e Zootecnia da Faculdade de Engenharia do Câmpus de Ilha Soltera (FEIS) da UNESP, vinculado como docente permanente aos Programa de Pós-Graduação em Ensino e Processos Formativos e Programa de Pós-Graduação em Educação para a Ciência (ambos da UNESP), líder do "Grupo de Pesquisa em Currículo: Estudos, Práticas e Avaliação (GEPAC)", harryson. lessa@unesp.br 